1 Title: Celebrating 50 years of the International Society for Prosthetics and Orthotics: Past,

2 Present, and Future

3

4 Running Head: Editorial: 50 Years of ISPO

5

6 Authors: SARAH ANDERSON Ph.D ${ }^{1}$, CLEVELAND T. BARNETT Ph.D ${ }^{2}$, DAVID F. RUSAW

$7 \quad \mathrm{Ph} . \mathrm{D}^{3}$.

$8{ }^{1}$ School of Allied Health, Human Services, and Sport, La Trobe University, Melbourne, Australia

$9 \quad{ }^{2}$ School of Science and Technology, Nottingham Trent University, Nottingham, U.K.

$10 \quad{ }^{3}$ School of Health and Welfare, Jönköping University, Jönköping, Sweden.

11

12

13

14

15 Conflict of Interest Statement

16 The authors report no conflicts of interest. The authors alone are responsible for the content and

17 writing of the paper.

18 
20 The International Society for Prosthetics and Orthotics (ISPO) is a non-governmental organization that,

21 since its establishment in the 1970s, has worked globally to improve the quality of life for people that use or may benefit from prosthetic and orthotic devices, as well as other assistive technology. ${ }^{1}$ ISPO's modern vision is a "world where all people have equal opportunity for full participation in society". ${ }^{2}$ The Society's journal, Prosthetics and Orthotics International, supports this vision by providing an avenue for the dissemination of peer-reviewed research that supports evidence-based-practice, promoting participation in society by people who use prostheses, orthoses, and assistive technologies.

27 In celebration of the ISPO's $50^{\text {th }}$ anniversary, the Executive Board asked that a special edition of

28 Prosthetics and Orthotics International be published to commemorate the role that the ISPO has played in

29 contributing to the development of knowledge in the field over the past 50 years. We reflected on the

30 inaugural edition of Prosthetics and Orthotics International from 1977, where one article drew our

31 attention and offered an exciting framework for this edition. The article, which was titled Education in

32 Prosthetics and Orthotics and authored by Dr. Sidney Fishman, ${ }^{3}$ spoke of the need for institutionalized

33 education and training to ensure that every clinician working in prosthetics and orthotics could demonstrate

34 the competencies necessary to provide safe and effective clinical services.

35 In considering what a contemporary curriculum might look like for the education of clinicians, Dr.

36 Fishman identified a core set of skills, capabilities, and knowledge that he summarized under the following 37 domains:

- Physical sciences, including mathematics

- Biological sciences

- Psychological sciences

- Mechanical skills and crafts

- Communication skills

44 At first glance, the competencies encompassed by these six domains may not seem relevant to the education of contemporary clinicians; particularly given Dr. Fishman's focus on basic sciences. However, 
we posit that a thoughtful exploration of each domain will highlight how these core competencies, first described by Dr. Fishman, have developed and where they are still required of a clinician working in prosthetics and orthotics today. Hence, our use of this seminal article by Dr. Fishman as the framework for this $50^{\text {th }}$-anniversary editon.

We invited subject experts to author evidence-based commentaries on how these varied competency areas have evolved over the last 50 years. To address this variety and, in keeping with ISPO's multidisciplinary scope, we solicited articles from individuals with varied professional backgrounds. Authors were encouraged to reflect on what Dr. Fishman proposed 50 years ago, and reflected on some key questions; how prosthetics and orthotics has changed, the role research has played in shaping our understanding, how research has been translated into clinical practice, and what the next 50 years might hold for the field. In this editorial, we are proud to introduce these invited contributions and provide some context for their foci.

\section{Contributions to this issue}

58 The response we received from invited authors was overwhelmingly positive and speaks to the engagement

59 of individuals currently contributing to research and education in our field. It is clear from the invited

60 commentaries contained in this special edition that many of the competencies first articulated by Dr.

61 Fishman have endured over the last 50 years, remaining critical competencies for prosthetists and orthotists today. The domains that Dr. Fishman discussed in 1977 were, in many ways, ahead of their time, given their relevance outside of the immediate remit of the profession. While still relevant today, these domains sometimes seemed narrow to current-day authors, reflecting perhaps how far understanding has advanced. Using communication skills as an example ${ }^{4}$ Dr. Fishman suggested a rather narrow definition, focused primarily on the spoken word, whereas the communication skills that prosthetists and orthotists use today vary widely. For example, the use of information technologies (IT) for non-physical consultations as discussed in the commentary on communication skills, ${ }^{4}$ represents an advance pertinent to prosthetics and orthotics that was not widely foreseen in 1977. As an understanding of communication, psychological sciences, and mechanical sciences on clinical practice and prosthesis and orthosis users ${ }^{4-8}$ has progressed and expanded over time, it is with hindsight that we can identify limitations to what was forecast approximately 50 years ago. This is a privileged perspective and the commentaries are enlightening with regard to historical limitations. 
74 Several of the invited authors have focused on the contribution that Prosthetics and Orthotics

75 International, has made in documenting the professional and academic development of our field. In the

76 areas of biological ${ }^{7}$ and physical sciences, ${ }^{8}$ for example, Prosthetics and Orthotics International has

77 contributed to the body of knowledge regarding developments in prosthetic interface and component

78 design, and the application of biomechanical principles to prosthetics and orthotics. Dr. Fishman

79 highlighted these areas as fundamental in 1977, and these commentaries discussing developments over the

80 past 50 years, have confirmed their lasting relevance.

81 What is evident from the commentaries presented in this edition, is that while there has been a substantial

82 volume of research over the past 50 years in some domains, others, such as the communication ${ }^{4}$ and

83 psychological sciences domains, ${ }^{6}$ have received comparatively less attention. However, it is heartening

84 that, in the area of psychological sciences, encouraging developments are identified, including both greater

85 focus on, and subsequent increase in, the number of publications examining psychosocial factors related to

86 prosthesis and orthosis users.

87 Considering treatment from a life-span perspective is important, given that prosthetic and orthotic

88 interventions are often long-term,.the need for clinicians to adopt a long-term perspective was raised as a

89 critical component of developing and providing effective care. Aging populations were also identified as a

90 topic of great relevance to future care in the commentaries focusing on professional communication, ${ }^{4}$

91 education, ${ }^{9}$ and psychological sciences ${ }^{6}$.

92 The role that advanced technological solutions may play in improving care in the future was also a

93 common theme among the commentaries..$^{4-9}$ For example, technology is having a particular influence on

94 how we deliver education programs and training to a wider student population. Given the ongoing effort to

95 increase the number of prosthetic and orthotic graduates in order to fulfil healthcare needs around the

96 world, ${ }^{10,11}$ the field must consider the role of technology in this process. Additionally, as more

97 communication between users and clinicians occurs digitally, ensuring quality in this communication will

98 require us to have a thorough understanding of the facilitative role of information technology.

99 The original article by Dr. Fishman had a clear educational focus; not surprising given that Dr. Fishman

100 was a renowned educator who developed and directed the first accredited four-year college-level program

101 in prosthetics and orthotics at New York University in the United States. ${ }^{12}$ We recognize that our 
102 understanding and delivery of prosthetic and orthotic education has also progressed over the last half-

103 century, prompting us to include a specific commentary on this topic in this special edition. ${ }^{9}$ While almost

10450 years may have passed since Dr. Fishman first described the skills, capabilities, and knowledge required

105 of prosthetists and orthotists, we believe that educators today share the same timeless goals of ensuring that

106 every prosthetist and orthotist demonstrates the competencies necessary to meet the needs of prosthesis and

107 orthosis users through provision of a safe and effective clinical service.

108 The future is bright and multidisciplinary

109 What is apparent from the commentaries in this special edition is the variety of professions, skills,

110 technologies, and scientific advances that have both benefited from and been enriched by the field of

111 prosthetics and orthotics. The significant changes that have occurred are perhaps a consequence of the field

112 being, at its very core, multifaceted and multi-disciplinary. Prosthetics and orthotics has historically been

113 open-minded with regards to looking externally for inspiration, and thus the influence of parallel fields has

114 enhanced prosthetics and orthotics by providing an outside perspective. This synergy and open-mindedness

115 has benefitted both prosthetics and orthotics and those fields with which it interacts.

116 Irrespective of what the future holds for the field of prosthetics and orthotics, we are confident that the

117 ISPO will continue to play an active role by providing a multi-disciplinary platform for high-quality

118 research through the publication of Prosthetics and Orthotics International. By continuing to support

119 clinicians and researchers in the dissemination of relevant and high-quality research, we can ensure that the

120 ISPO - and Prosthetics and Orthotics International remain active contributors during the coming 50 years,

121 thus helping to improve the quality of life for prosthesis and orthosis users, regardless of where future

122 developments take us.

\section{Acknowledgments}

125 The Guest Editors of this special edition would like to extend our gratitude to the invited authors for their

126 hard work and vision in bringing this special edition together. Similarly, we are grateful for the input from

127 our expert peer-reviewers, whose feedback was invaluable. Finally, we would like to thank the Editors-in-

128 Chief of Prosthetics and Orthotics International for their support during the completion of this enterprise. 
130 Word Count: 1456 
1.

ISPO. International Society for Prosthetics and Orthotics - History, https://www.ispoint.org/page/history2 (2020, accessed 2020-09-24 2020).

$1373 . \quad$ Fishman S. Education in prosthetics and orthotics. Prosthetics and Orthotics 138 International $1977 ; 1: 52-55$.

1394 4. van Netten J, Jarl G, Postema K, et al. A toolkit for prosthetists and orthotists to 140 facilitate progress in professional communication the next 50 years. Prosthet Orthot Int 2020; 44 $1415 . \quad$ Boone DA. Prosthetists and Orthotists: An Evolution from Mechanic to Clinician. $142 \quad$ Prosthet Orthot Int 2020; 44.

1436 6. Desmond D. Reflections and future directions for psychological science in 144 Prosthetics and Orthotics International Prosthet Orthot Int 2020; 44.

$1457 . \quad$ Safari R. Lower Limb Prosthetic Interfaces; Clinical and Technological 146 Advancement and Potential Future Direction Prosthet Orthot Int 2020; 44.

$147 \quad 8 . \quad$ Stephens P. Physical Sciences. Prosthet Orthot Int 2020; 44.

1489 . Owens E. Education in prosthetic and orthotic training: looking back 50 years and 149 moving forward. Prosthet Orthot Int 2020; 44.

$15010 . \quad$ Corathers Health Consulting. The Orthotic and Prosthetic Profession: A 151 Workforce Demand Study. National Commission on Orthotic and Prosthetic Education and 152 American Orthotic \& Prosthetic Association, 2006.

153 11. Nielsen CC. Issues Affecting the Future Demand for Orthotists and Prosthetists:

154 Update 2002 : a Study Updated for the National Commission on Orthotic and Prosthetic 155 Education, May 2002. National Commission on Orthotic and Prosthetic Education, 2002.

$156 \quad 12 . \quad$ Edge TOP. Renowned Educator Sidney Fishman Dies,

157 https://opedge.com/Articles/ViewArticle/news_2005-04-04_05 (2005, accessed 2020-09-24

158 2020). 